\title{
Bacterial Decomposition of Extractive Matter of Meat of Aquatic Animals.*
}

\author{
V. Relation between the Bacterial Decomposition and the \\ Surface Tension of the Solution of the Extractive Matter.
}

\section{Masao KIMATA}

(The Imperial Fisheries Institute, Tôkyô)

The relation of surface tension to bacterial development has hitherto been reported by several investigators. But, as for the relation between the bacterial decomposition of the medium and its surface tension, little is known, so far as I am aware.

The present paper embodies my observations on the effect of surface tension upon the bacterial decomposition of the solution of extractive matter of meat of Scomber japonicus (Houtrurs).

Medium used was prepared by the method previously reported. ${ }^{(1)}$ Fifty c.c. of this medium were pipetted into several flasks of capacity of 200 c.c. Various quantities of Na-recinoleate were added to each flask, which was filled up to 100 c.c. with distilled water and then sterilized. These flasks were inoculated with bacteria. (Pseudomonas fluorescens or Serratia marcescens) and were incubated at $26^{\circ} \mathrm{C}$. At the regular intervals, 5 c.c. of the mixture were taken out from each of these flasks, and the surface tension and formol titrating nitrogen were measured.

Results obtained are shown in Fig. 1. From this figure it is clear that the velocity of the decomposition increases with depression in the initial surface tension (as is justified from inclination of the lines in Fig. B), and that the rate of the decomposition is almost constant, without regard to the surface tension. The surface tension changes with bacterial growth (namely with the decomposition of the medium), but ceases to change when the process of the decomposition reaches equilibrium, and at this time it becomes almost the same irrespective of the different initial surface tension.

It is not clear whether those effects are due to the surface tension or to the chemical nature of the depressant. But those effects seem to be due to the former rather than to the latter, within the limits of concentration of the depressant employed. ${ }^{(2)}$

* This work was supported in part by a grant from "Nippon Gakuzyutu Sinkôkai."

(1) Kimat A, M: Bull. Jap. Soc. Sei. Fish. 5, 1937, 349.

(2) Kimata, M: To be published in future. 

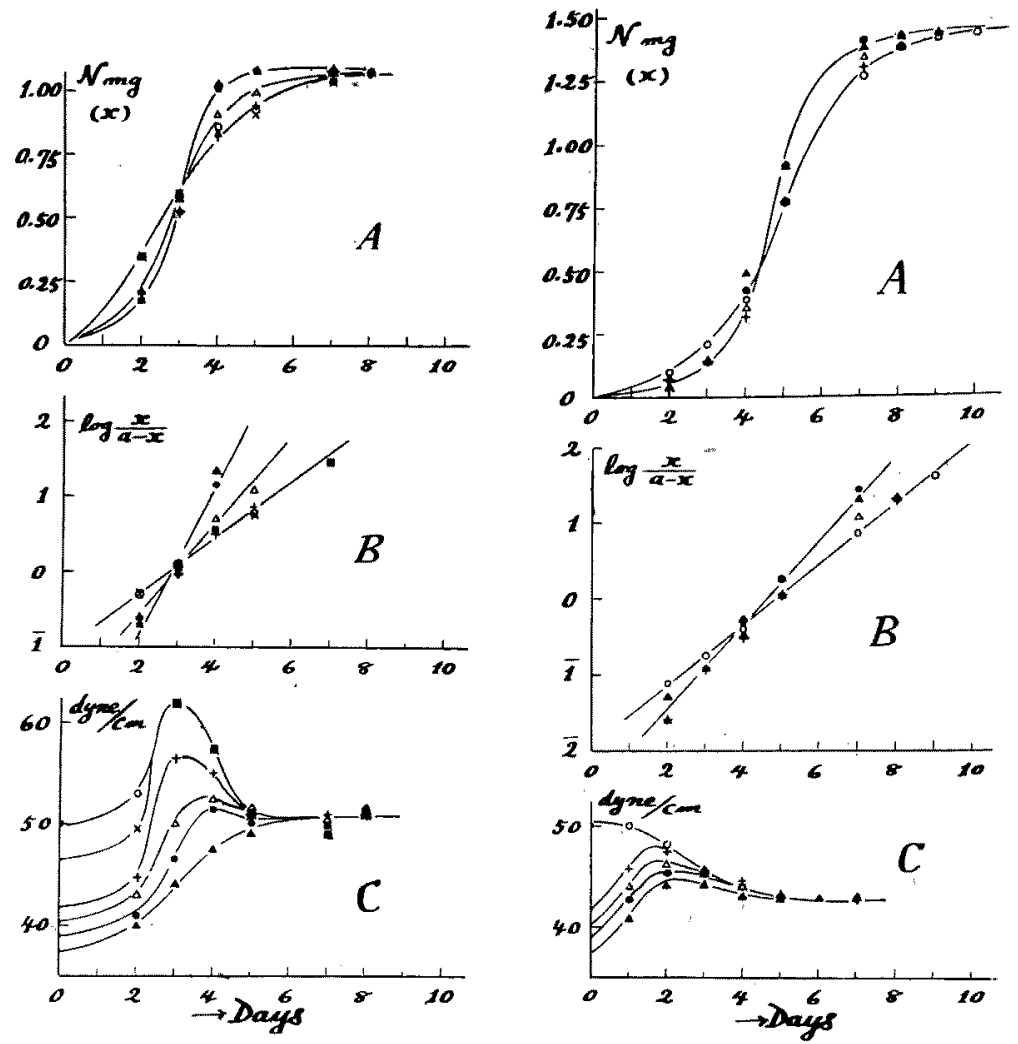

Fig. 1. Left...Pseudomonas fluorescens. Right....Serratia marcescens.

A ... Production of formal titrating nitrogen plotted against time (in 5 c.c.).

$B \cdots$ Relation between $\log _{a-x} \frac{x}{a n d ~ t i m e . ~}$

$C$... Change of the surface tension plotted against time.

O...0\% Na-recinoleaté (control)

$+\cdots 0001 \%$

$\times \cdots 0.0005 \%$ Na-recinoleate

.... $0.005 \%$

$\triangle \cdots 0.0025 \%$

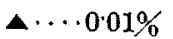

